\title{
Alpha-Mangostin Activates MOAP-1 Tumor Suppressor and Mitochondrial Signaling in MCF-7 Human Breast Cancer Cells
}

\author{
Samson Eugin Simon (D, Hui Sin Lim (D), Fairen Angelin Jayakumar (D, \\ Ee Wern Tan $\mathbb{D}$, and Kuan Onn Tan $\mathbb{D}$ \\ Cancer Biology Group, Department of Biological Sciences, School of Medical and Life Sciences, Sunway University, \\ No. 5 Jalan Universiti, Subang Jaya 47500, Selangor Darul Ehsan, Malaysia
}

Correspondence should be addressed to Kuan Onn Tan; jefft@sunway.edu.my

Received 19 July 2021; Revised 13 October 2021; Accepted 13 December 2021; Published 17 January 2022

Academic Editor: Siyaram Pandey

Copyright (c) 2022 Samson Eugin Simon et al. This is an open access article distributed under the Creative Commons Attribution License, which permits unrestricted use, distribution, and reproduction in any medium, provided the original work is properly cited.

$\alpha$-Mangostin, one of the major constituents of Garcinia mangostana, has been reported to possess several biological activities, including antioxidant, anti-inflammatory, antibacterial, and cytotoxic activities associated with the inhibition of cell proliferation and activation of apoptosis. However, the cellular signaling pathway mediated by $\alpha$-mangostin has not been firmly established. To investigate the cellular activities of $\alpha$-mangostin, human cancer cells, MCF-7 and MCF-7-CR cells, were treated with $\alpha$-mangostin to measure the cellular responses, including cytotoxicity, protein-protein interaction, and protein expression. Cancer cells stably expressed Myc-BCL-XL and HA-MOAP-1 were also included in the studies to delineate the cell signaling events mediated by $\alpha$-mangostin. Our results showed that the apoptosis signaling mediated by $\alpha$-mangostin involves the upregulation of endogenous MOAP-1, which interacts with $\alpha$-mangostin activated BAX (act-BAX) while downregulating the expression of BCL-XL. Moreover, $\alpha$-mangostin was found to induce BAX oligomerization, the release of mitochondrial cytochrome $\mathrm{C}$, and activation of caspase in MCF-7 cells. In overexpression studies, MCF-7 cells and spheroids stably expressed HA-MOAP-1 and Myc-BCL-XL exhibited differential chemosensitivity toward $\alpha$-mangostin in which the stable clones expressing HA-MOAP-1 and MYC-BCL$\mathrm{XL}$ were chemosensitive and chemoresistant to the apoptosis signaling events mediated by $\alpha$-mangostin, respectively, when compared to untreated cells. Together, the data suggest that the cytotoxicity of $\alpha$-mangostin involves the activation of MOAP-1 tumor suppressor and its interaction with act-BAX, leading to mitochondria dysfunction and cell death.

\section{Introduction}

Natural products derived from G. mangostana L. (Clusiaceae) have been used traditionally for wound healing or as antimicrobial and antiparasitic agents to treat dysentery or skin infection in many parts of Asia, including Malaysia, Thailand, and China [1-3]. The anti-inflammatory property of G.mangostana has been exploited for the treatments of eczema and psoriasis [4-6]. Phytochemical studies of G.mangostana have identified xanthones as the major constituents, particularly $\alpha$-mangostin [7-10].

In addition, natural products derived from G. mangostana are known to exhibit cytotoxic effects on cancer cells [4, 11-14]. However, the mechanisms of action of these natural products have not been firmly established. In fact, $\alpha$-mangostin isolated from $G$. mangostana has been reported to mediate ROS-associated cytotoxicity [12, 15], apoptosis, anti-inflammatory, and antimicrobial activities $[12,16]$. Moreover, $\alpha$-mangostin has been shown to inhibit the expression of MMP2 and MMP9 and to promote the release of endonuclease- $G$ from mitochondria through caspase-independent apoptosis $[12,14,17]$.

Conventional chemotherapies rely on small molecule chemotherapy drugs to induce cytotoxicity in fast-dividing cancer cells, including small molecules derived from natural resources such as xanthones isolated from G. mangostana that were reported to mediate cytotoxic effects on cancer cells $[18,19]$. However, cancer cells are known to develop 
resistance to chemotherapy, rendering chemotherapy drugs ineffective, and higher doses of chemotherapy drugs may be required to achieve the therapeutic outcome [20-23]. In addition, cancer treatments that utilize high doses of chemotherapy drugs are associated with cellular cytotoxicity, including the weakening of the immune system that gives rise to opportunistic infections [24-26]. Therefore, high potency anticancer drugs that exhibit high specificity and low cytotoxic effects are likely to be efficacious for cancer treatment by targeting specific features of cancer cells, including the mitochondria which are the prime source of ATP production that is required to sustain the growth of cancer cells $[27,28]$.

One of the important mitochondrial signaling molecules is $\mathrm{BAX}$, which is a proapoptotic member of the Bcl-2 family, and it is activated by a receptor-mediated signaling mechanism that involves MOAP-1 and RASSF1A through TNF and TRAIL receptors mediated apoptotic signaling mechanism [29-33]. MOAP-1 takes part in the apoptotic signaling by interacting with BAX through its BH3-like domain, leading to BAX activation and oligomerization at the mitochondria [23, 34-37]. Oligomerization of BAX induces depolarization of mitochondria membrane potential and release of mitochondrial cytochrome $\mathrm{C}$ that ramps up the activation of apoptosome and caspases [30, 33, 38-44].

To evaluate the cytotoxicity of $\alpha$-mangostin and to determine its potential interaction with molecules associated with mitochondria, both endogenous and overexpressed mitochondria-associated proteins, including MOAP-1 and BCL-XL, were included in this investigation. Overexpression of the exogenous proteins in the cancer cells offers added advantages in which the cellular activity of the overexpressed protein in the $\alpha$-mangostin treated cells can be studied, evaluated, and compared to other proteins, including negative control, that are similarly overexpressed under the same experimental paradigms. Our results showed that $\alpha$-mangostin activates downstream apoptosis signaling events, leading to mitochondria dysfunction and cell death.

\section{Methods}

2.1. Reagents and Antibodies. $\alpha$-Mangostin (99\% purity, prepared in DMSO), AlamarBlue ${ }^{\circledast}$ cell viability reagents, DAPI, Annexin- $\mathrm{V}$ apoptosis reagent, antimouse secondary antibody conjugated to Horseradish Peroxidase, and Protein A agarose were purchased from Thermofisher (Waltham, MA, USA). Z-VAD-fmk, a pan-caspase inhibitor, was obtained from MedChem Express (Monmouth Junction, NJ, USA). Antibodies against MOAP-1 (A11, Sc-271338), BCLXL (H-5, sc-8392), BAX (6A7, sc-23959, sc-7480), BAX (N20, sc-493), Cytochrome C (A8, sc-13156), HSP60 (F9, sc376261), and $\beta$-ACTIN (C4, sc-47778) were purchased from Santa Cruz Biotechnology (USA). Polyethyleneimine (Linear, MW 25000) was obtained from PolyScience (Niles, IL, USA). Caspase assay using pGLOSensor ${ }^{\mathrm{TM}}-30 \mathrm{~F}$ DEVD plasmid and ONE-Glo ${ }^{\mathrm{TM}}$ luciferase reagent was purchased from Promega (Madison, WI, USA). BMH crosslinking reagent was purchased from Tokyo Chemical Industry (Tokyo, Japan).
2.2. Cell Culture. The human breast epithelial cancer cell lines, MCF-7 (ATCC ${ }^{\circledR}$ HTB-22 ${ }^{\mathrm{TM}}$ ) and MCF-7-CR [45], which is a cisplatin-resistant clone of the MCF-7 cells and HaCaT cells (CLS Cell Lines Service, Germany, Cat: 300493) were maintained in Dulbecco's Modified Eagle Medium (DMEM) supplemented with $10 \%$ fetal bovine serum (FBS; Gibco), $2 \mathrm{mM}$ glutamine, $100 \mathrm{U} / \mathrm{ml}$ penicillin, and $100 \mu \mathrm{g} / \mathrm{ml}$ streptomycin (Sigma), at $37^{\circ} \mathrm{C}$ in a humidified atmosphere with $5 \% \mathrm{CO}_{2}$.

2.3. Cell Viability Assay and Selectivity Index. MCF-7, MCF7-CR, and $\mathrm{HaCaT}$ cells were seeded in a 96-well plate at a density of $1.5 \times 10^{4}$ cells/well and allowed to grow for $48 \mathrm{~h}$. The cells were then treated with various concentrations of $\alpha$-mangostin. Cell viability was determined using Alamar Blue or MTT reagent, and the percent cell viability was normalized against untreated cells. The dose-dependent inhibition concentrations $\left(\mathrm{IC}_{50}\right)$ of $\alpha$-mangostin were determined in MCF-7 and MCF-7-CR cells using Graph$\mathrm{Pad}$ Prism. To determine the selectivity index of $\alpha$-mangostin, the IC50 value of $\mathrm{HaCaT}$ cells was divided by the respective IC50 value of MCF-7 and MCF-7-CR cells.

2.4. Stable Clone Selection. MCF-7 cells were seeded in a $60 \mathrm{~mm}$ plate and transfected for $6 \mathrm{~h}$ with $5 \mu \mathrm{g}$ of pcDNAHA-MOAP-1, Myc-BCL-XL, or the vector. After transfection, cells were treated with $800 \mu \mathrm{g} / \mathrm{ml}$ of geneticin (G418) sulfate (Santa Cruz, USA) for three weeks. Media containing $800 \mu \mathrm{g} / \mathrm{ml}$ of G418 was changed once every three days. The selected stable clones were isolated using cloning rings and expanded for experiments while cultured in media containing $400 \mu \mathrm{g} / \mathrm{ml}$ of G418.

2.5. Spheroid Cell Depletion. MCF-7 spheroid cells were generated by dropping $30 \mu \mathrm{l}$ of media containing $1 \times 10^{3}$ of MCF-7 cells on UV treated sterile glass coverslip and inverted over in each well of 24 well plates containing sterile 1x PBS. After incubating for 48 h, $0.2 \%$ agarose gel at a temperature less than $50^{\circ} \mathrm{C}$ was prepared in DMEM containing $40 \%$ FBS and $100 \mu \mathrm{l}$ of the agarose gel mixture was transferred into a 24 well plate without air bubble and allowed to solidify. Hanging cells were then flushed with $100 \mu \mathrm{l}$ of $10 \%$ FBS complete media into wells containing the agarose gel mixture. The depletion of the spheroid mass was obtained by treating the spheroid cells with $\alpha$-mangostin and the cell viability of the spheroids was measured using Alamar Blue periodically from 0-5 days. The spheroid cell depletion was also monitored periodically for up to 5 days with the images captured under a microscope.

2.6. Flow Cytometry. Apoptosis of cancer cells was detected using Annexin-V APC and PI, according to the manufacturer's instruction. In brief, $4 \times 10^{5}$ of MCF-7 cells were seeded in 6-well plates at $80 \%$ confluency for $48 \mathrm{~h}$ followed by treatment with $\alpha$-mangostin $(10,20$, and $30 \mu \mathrm{M})$ 
overnight. The cells were subsequently stained with Annexin $\mathrm{V}$ and PI in the dark for 15 min followed by flow cytometry analysis (FACS Calibur, BD Biosciences).

2.7. Nuclear Condensation Assay. MCF-7 cells at a density of $4 \times 10^{5}$ cells/well were seeded on a sterile glass coverslip in 6well plates for $48 \mathrm{~h}$ and treated with $\alpha$-mangostin $(10,20$, and $30 \mu \mathrm{M})$. The cells were subsequently fixed using ice-cold methanol and stained with DAPI. Condensed nuclei were identified using a fluorescence microscope by counting the number of DAPI stained cells from five randomly selected fields under the fluorescence microscope (Nikon).

2.8. Western Blotting and Coimmunoprecipitation. MCF-7 cells were seeded equally in a $60 \mathrm{~mm}$ plate at a density of $1.4 \times 10^{6}$ cells/well. After $48 \mathrm{~h}$, the cells were treated with $\alpha$-mangostin for $12 \mathrm{~h}$. The cells were collected using a cell scraper and washed with $1 \mathrm{x}$ PBS. RIPA buffer $(50 \mathrm{mM}$ Tris$\mathrm{HCl}, \mathrm{pH} 7.5,150 \mathrm{mM} \mathrm{NaCl}, 1 \mathrm{mM}$ EDTA, $0.25 \% \mathrm{Na}-$ deoxycholate, $1 \%$ NP-40) containing protease inhibitors was added to the cells followed by incubation on ice for $15 \mathrm{~min}$. The cell pellets were vortexed to lyse the cells, and clear cell lysates were collected from the supernatants by centrifuging the cell lysates at $15000 \mathrm{xg}$ for $10 \mathrm{~min}$. Equal amounts of the cell lysates, as determined by protein concentration, were separated on $12.5 \%$ SDS-PAGE followed by Western blot analysis with antibodies to detect MOAP-1, BCl-XL, BAX, or $\beta$-ACTIN. Primary antibodies $(1: 1000)$ were probed overnight at $4^{\circ} \mathrm{C}$, and a secondary antibody conjugated to HRP $(1: 5000)$ was probed for $1 \mathrm{~h}$ at room temperature. For coimmunoprecipitation, MCF-7 cells were seeded equally in a $100 \mathrm{~mm}$ plate at a density of $2.5 \times 10^{6}$ cells per plate and treated as mentioned earlier. Cell lysates were prepared with CHAPS buffer (20 mM Tris- $\mathrm{HCl}, \mathrm{pH} 7.5,150 \mathrm{mM} \mathrm{NaCl}$, $0.2 \%$ Nonidet P-40, $1 \mathrm{mM}$ EDTA, protease inhibitors), and polyclonal anti-BAX antibody (N20) was added to the cell lysate for overnight incubation at $4^{\circ} \mathrm{C}$. Protein A agarose beads were subsequently added to the cell lysates followed by $4 \mathrm{~h}$ of incubation at $4^{\circ} \mathrm{C}$. The immunoprecipitates were analyzed through Western blot with the indicated antibodies. Signals were visualized using ECL reagent (Pierce) and detected using a Luminescent Image Analyzer LAS-4000 mini.

2.9. Mitochondrial Cytochrome C Release Assay. MCF-7 cells were seeded in a $60 \mathrm{~mm}$ plate at a density of $4 \times 10^{6}$ cells/plate. After $48 \mathrm{~h}$, the cells were treated with $\alpha$-mangostin $(10,20$, and $30 \mu \mathrm{M}$ ) for $12 \mathrm{~h}$. The cells were subsequently harvested and suspended in lysis buffer A (10 mM HEPES, pH 7.9, $10 \mathrm{mM} \mathrm{KCl}, 0.1 \mathrm{mM}$ EDTA, $1 \mathrm{mM}$ dithiothreitol) containing protease inhibitors followed by $15 \mathrm{~min}$ incubation on ice and vortexed. Using $25^{5 / 8}$ gauge needle, the cell suspension was expulsed through the needle 25 to 30 times and centrifuged at $1000 \times \mathrm{g}$ for $10 \mathrm{~min}$ to remove cell debris and nucleus. The supernatants containing cytosolic fractions were subsequently centrifuged for $10 \mathrm{~min}$ at $3000 \mathrm{xg}$ to pellet the mitochondria. The pellets were washed once with buffer A containing protease inhibitors and suspended in RIPA buffer $(50 \mathrm{mM}$ Tris at $\mathrm{pH} 7.5,150 \mathrm{mM} \mathrm{NaCl}, 1 \mathrm{mM}$ EDTA, $0.25 \% \mathrm{Na}-$ deoxycholate, $1 \%$ NP-40) containing protease inhibitors. The lysate was collected from the supernatant by centrifuging at $15000 \mathrm{xg}$ for $10 \mathrm{~min}$ followed by Western blot analysis using the indicated antibodies, including anti-Cytochrome $\mathrm{C}$ and HSP60 antibodies. The signals were visualized using ECL reagent (Pierce) and detected using a Luminescent Image Analyzer LAS-4000 mini.

2.10. Transfection and Caspase Assay. All transfection assays were performed using polyethyleneimine (PEI, Polyscience, Inc.). pGLO sensor-30F DEVD plasmid was used for caspase assay, which was performed using the Luciferase One-Glo assay kit (Promega, USA) according to the manufacturer's protocol. MCF-7 cells or MCF-7 stable clone cells were seeded in 24-well plates for caspase assay. At 70\% confluency, $0.5 \mu \mathrm{g}$ of $\mathrm{pGLO}$ sensor-30F DEVD plasmid was mixed with PEI $(1: 3)$ and incubated in serum-free media before adding the mixture to the MCF-7 cells for transfection. After $4 \mathrm{~h}$ of transfection, fresh media containing $10 \%$ FBS was added and incubated in a $37^{\circ} \mathrm{C}$ incubator for $24 \mathrm{~h}$ followed by treatment with $\alpha$-mangostin for $12 \mathrm{~h}$. For cells treated with Z-VAD-fmk caspase inhibitor, the inhibitor was added $1 \mathrm{~h}$ before the $\alpha$-mangostin treatment. The cells were harvested and One-Glo luciferase reagent was added to the cell lysate, and fluorescent readings were obtained through the multiplate reader and normalized with the readings obtained from control cells.

2.11. BMH Chemical Cross-Linking. MCF-7 cells were seeded equally in a $100 \mathrm{~mm}$ plate at a density of $2.5 \times 10^{6}$ cells. At $80 \%$ confluency, the MCF-7 cells were treated for $8 \mathrm{~h}$ with $30 \mathrm{uM} \alpha$-mangostin. The cells were harvested and lysed in CHAPS buffer (20 mM Tris, pH 7.5, $150 \mathrm{mM} \mathrm{NaCl}, 0.2 \%$ Nonidet P-40, $1 \mathrm{mM}$ EDTA, protease inhibitors). Protein concentration was quantified using BCA reagent according to the manufacturer's protocol, and $0.5 \mathrm{mg}$ of protein was mixed with $0.5 \mathrm{ml} 2 \mathrm{X}$ PBS along with $100 \mu \mathrm{M}$ BMH crosslinking reagent for $45 \mathrm{~min}$. The reaction was subsequently quenched using $0.5 \mathrm{mM}$ DTT and incubated for $15 \mathrm{~min}$. Western blot was performed as mentioned previously, with the indicated antibody.

2.12. Statistical Analysis. The results are presented as mean \pm standard error (S.E.) from three independent experiments. Data were analyzed using the GraphPad Prism 8.0 or Excel Spreadsheet. Student's $t$-test or ANOVA was performed to determine whether the observed differences in the data were statistically significant as represented by $p$-value, $p<0.05$ or $p<0.001$. 


\section{Results}

To characterize potential novel cell signaling pathways mediated by $\alpha$-mangostin in cancer cells, MCF-7 and MCF7-CR cells were treated with different concentrations of $\alpha$-mangostin, and the IC50 and selectivity index values based on the cell viability of $\alpha$-mangostin-treated cells were determined (Figures 1(a)-1(c)). The cytotoxicity of $\alpha$-mangostin on MCF-7 spheroid cells was also examined (Figures 1(d)-1(e)). In these models, $\alpha$-mangostin induced both time- and dose-dependent loss of cell viability on the human cancer cells.

To determine whether the cytotoxic effect of $\alpha$-mangostin involves necrosis or apoptosis, MCF-7 cells were treated with $\alpha$-mangostin for $18 \mathrm{~h}$, and the cells were stained with Annexin-V and propidium iodide followed by flow cytometry analysis. As shown in Figures 2(a)-2(d)), $\alpha$-mangostin induced dose-dependent apoptotic cell death in MCF-7 cells, resulting in positive staining with Annexin$\mathrm{V}$, caspase activation, and nuclei condensation, indicating $\alpha$-mangostin possesses high potency in inducing apoptotic cell death in MCF-7 cells.

To identify the mechanism of apoptosis mediated by $\alpha$-mangostin, MCF-7 cells were treated with different concentrations of $\alpha$-mangostin, and the cell lysates were prepared for Western blot analysis with antibodies specific for the proapoptotic and antiapoptotic proteins, including BAX, MOAP-1, and BCL-XL. As shown in Figure 3(a), MCF-7 cells treated with $\alpha$-mangostin showed dose-dependent upregulation and downregulation of endogenous MOAP-1 and $\mathrm{BCl}-\mathrm{XL}$ proteins, respectively, while the protein level of proapoptotic BAX remained relatively constant under the same treatment condition (Figure 3(a)). In addition, the cellular effects of $\alpha$-mangostin coincided with its activity in mediating the dose-dependent release of mitochondrial Cyt. $\mathrm{C}$ in MCF-7 cells treated with $\alpha$-mangostin (Figure 3(b)).

Since BAX was reported to interact with MOAP-1, the level of BAX activation and its association with MOAP-1 were determined using a coimmunoprecipitation assay. As shown in Figure 3(c), MCF-7 cells treated with increasing concentration of $\alpha$-mangostin showed dose-dependent upregulation of activated BAX (act-BAX), which coimmunoprecipitated with MOAP-1 (Figure 3(c)). The activated BAX was shown to coimmunoprecipitate with MOAP-1 when MCF-7 cells were treated with $\alpha$-mangostin (Figures 3(c)), which at these concentrations coincided with the substantial release of Cyt. C from mitochondria (Figure 3(b)), suggesting that $\alpha$-mangostin induces apoptosis signaling by promoting the interaction of act-BAX with MOAP-1, leading to the release of mitochondrial Cytochrome C. Furthermore, $\alpha$-mangostin induced oligomerization of BAX (Figure $3(\mathrm{~d})$ ), and the BMH cross-linked BAX oligomers were identified by the anti-BAX antibody.

To further substantiate the role of MOAP- 1 in $\alpha$-mangostin-mediated apoptosis signaling, stable clones of MCF-7 cells overexpressed HA-MOAP-1 or Myc-BCL-XL were generated, and the expressed proteins were detected using Western blot (Figure 4(a)). HA-MOAP-1 and Myc-BCl-XL were dose-dependently upregulated and downregulated, respectively, when the respective stable clones were treated with $\alpha$-mangostin (Figure $4(\mathrm{~b})$ ). In addition, the stable clone expressed HA-MOAP-1 showed a high level of chemosensitization toward $\alpha$-mangostin when compared to MycBCL-XL or vector stable clone as evidenced by the dosedependent release of mitochondrial Cyt.C and activation of caspase (Figures 4(c)-4(d)).

The MCF-7 stable clones were further evaluated using $3 \mathrm{D}$ spheroid cell model in which the spheroids were treated with $\alpha$-mangostin for 3 days. Spheroid cells expressed HAMOAP-1 responded the most to the treatment with $\alpha$-mangostin, resulting in time-dependent loss of cell viability in which the spheroid cells lost close to $90 \%$ of their cell viability after 3 -day of treatment with $\alpha$-mangostin (Figures 4(e)-4(f)). In comparison, the spheroid cells expressed Myc-BCl-XL or vector lost $11 \%$ or $32 \%$ of cell viability, respectively, under the same treatment (Figures 4(e)-4(f)), suggesting that $\alpha$-mangostin activates MOAP-1-mediated apoptosis signaling, while BCL-XL confers protection and antagonizes the apoptosis signaling mediated by $\alpha$-mangostin in MCF-7 cells.

\section{Discussion}

Small molecules ( $<500$ Daltons) that are targeting cell signaling pathways offer an alternative treatment option for cancer. To identify high potency bioactive compounds, bioassays were used to characterize the cytotoxicity of $\alpha$-mangostin, including its potential interaction with the mitochondria signaling pathway. Our results showed that $\alpha$-mangostin exhibits selective cytotoxicity against MCF-7 and MCF-7 cells with relative high selective index $(\mathrm{SI}>40)$, when compared to HaCaT cells $[47,48]$. The selective cytotoxicity of $\alpha$-mangostin was also reported in leukemic cancer cells [49]. The cytotoxicity of $\alpha$-mangostin involved activation of apoptosis signaling mediated by MOAP- 1 and the interaction of MOAP-1 with act-BAX, leading to oligomerization of $\mathrm{BAX}$, the release of mitochondrial cytochrome C, and apoptosis (Figure 5). The results are consistent with the reported findings that showed that $\alpha$-mangostin induced apoptosis by activating cell cycle arrest or ASK/p38 signaling pathway in oral squamous cell carcinoma and cervical cancer cells, respectively [50, 51]. Taken together our data thus suggest that the apoptosis signaling mediated by $\alpha$-mangostin in human cancer cells that involves the activation of MOAP-1 and BAX is likely to impact on other signaling pathways activated by $\alpha$-mangostin, such as cell cycle arrest, leading to apoptotic cell death. The role of mitochondria in the regulation of cell cycle and cell proliferation has been reported [52].

Interestingly, when MCF-7 cells were treated with $\alpha$-mangostin, the protein level of the BCL-XL decreased dose-dependently. The downregulation of BCL-XL mediated by the activators of apoptosis was previously reported $[53,54]$ and the mechanisms involved protein degradation mediated by proteasomal pathway and cleavage by proteolytic enzyme. As BCL-XL is known to interact with both proapoptotic BAX and MOAP-1 [36, 55-58], the downregulation of $\mathrm{BCL}-\mathrm{XL}$ is likely to facilitate the activation of 


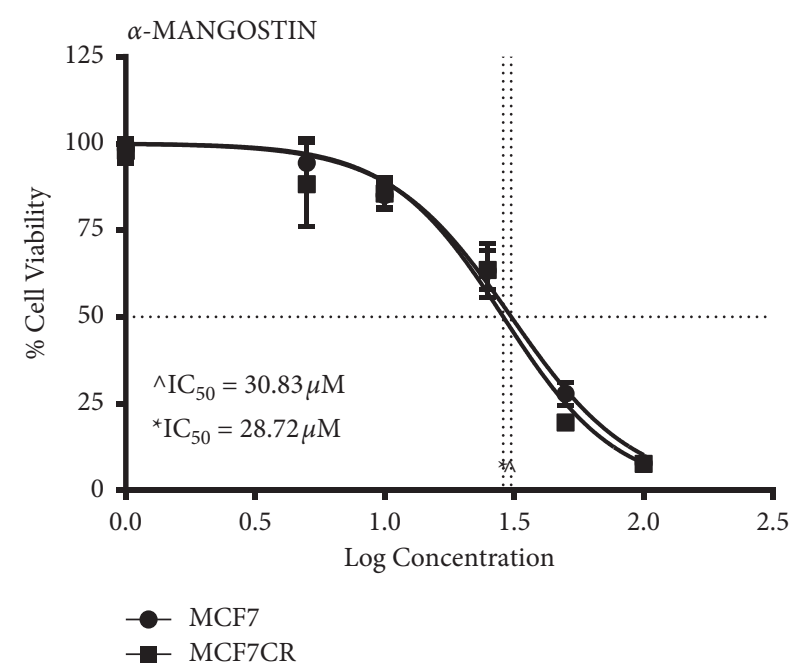

(a)

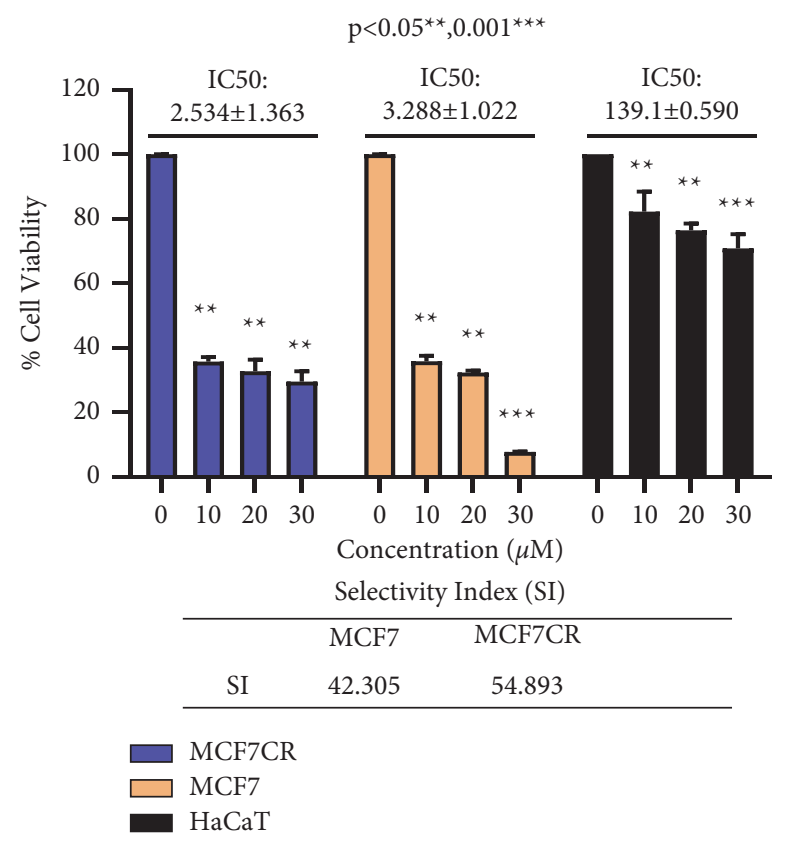

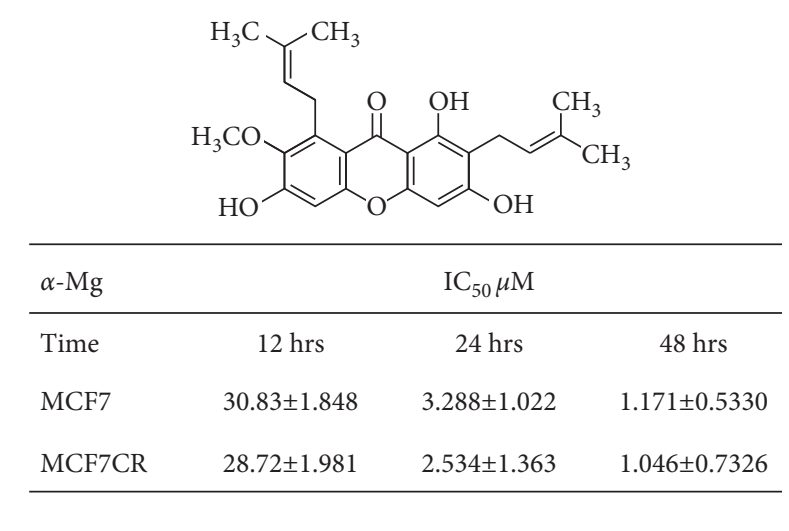

(b)

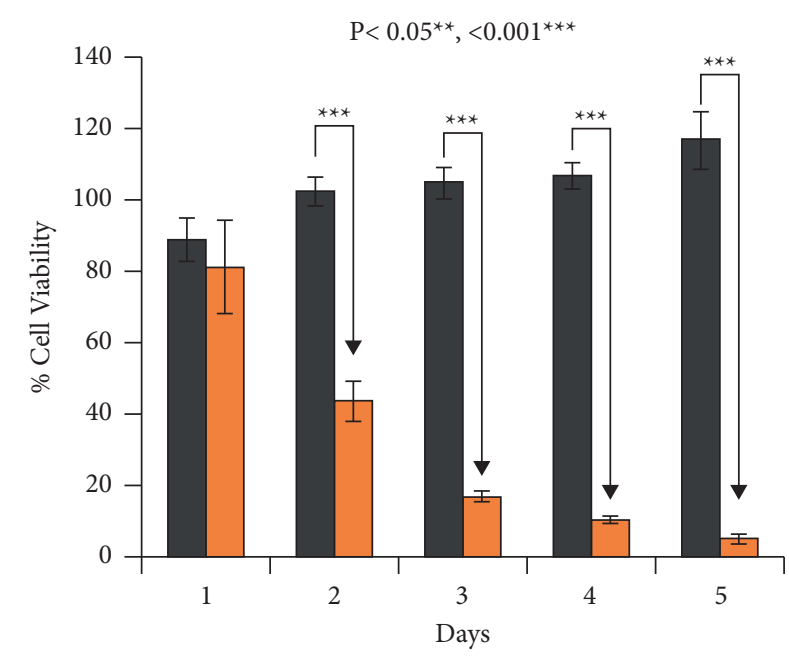

DMS0 1\%

$\alpha-\operatorname{Mg} 30 \mu \mathrm{m}$

(c)

(d)

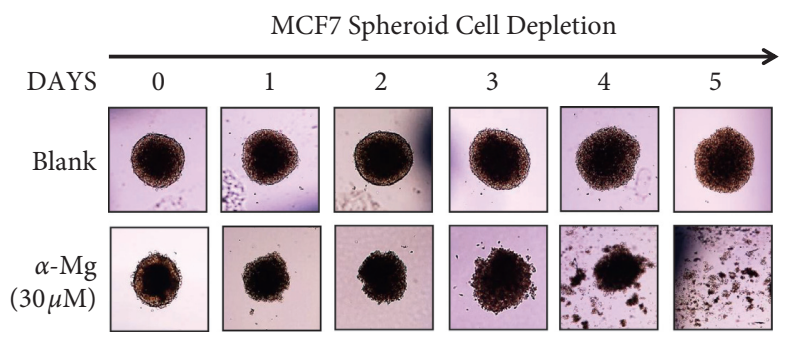

(e)

FIGURE 1: Cytotoxic effects of $\alpha$-mangostin on cancer cell lines and spheroid cells. (a, b) Cytotoxicity of $\alpha$-mangostin on human cell lines. The cell lines were treated with different concentrations of $\alpha$-mangostin for $12 \mathrm{~h}$ (a) or extended up to $48 \mathrm{~h}$ (b) and the cell viability of the cells was measured to determine the IC50 values. (c) Selectivity index (SI) of $\alpha$-mangostin. The cells were treated with the indicated concentration of $\alpha$-mangostin, and the IC50 values of the treated cells were obtained. SI value of $\alpha$-mangostin was determined in MCF-7 and MCF-7-CR as described in Methods section. (d) Time-dependent loss of cell viability of MCF-7 spheroid cells treated with $\alpha$-mangostin. The cell viability of the spheroid cells was measured after treatment with $\alpha$-mangostin at the indicated time. For control, the cells were treated with $1 \%$ DMSO (vol/vol) in the cell culture media, and the results from the control were used to normalize the data. (e) Morphology of $\alpha$-mangostin-treated MCF-7 spheroid cells. 


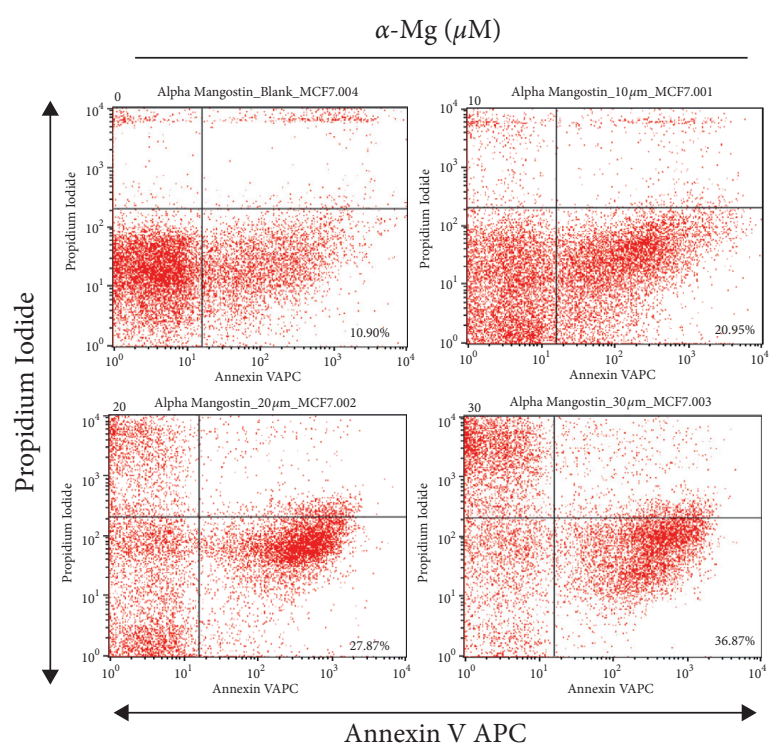

(a)

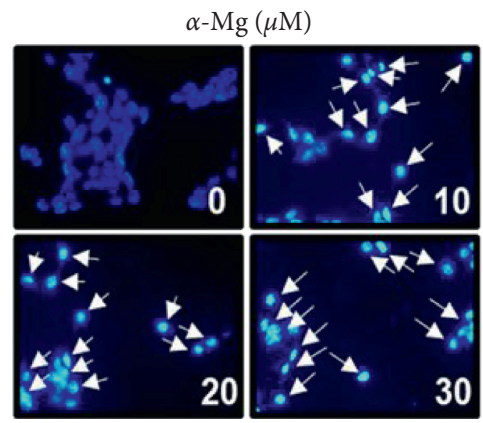

30

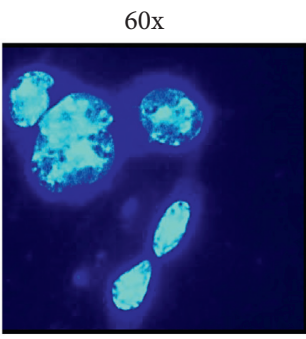

$\alpha-\operatorname{Mg}(30 \mu \mathrm{M})$

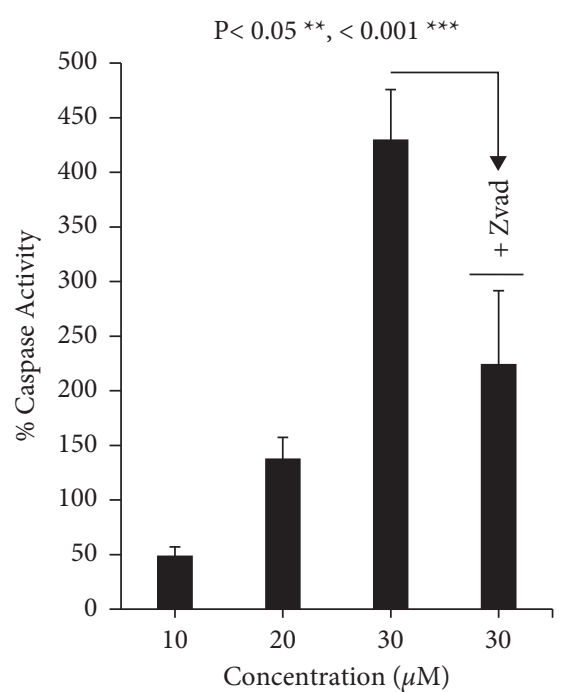

(b)

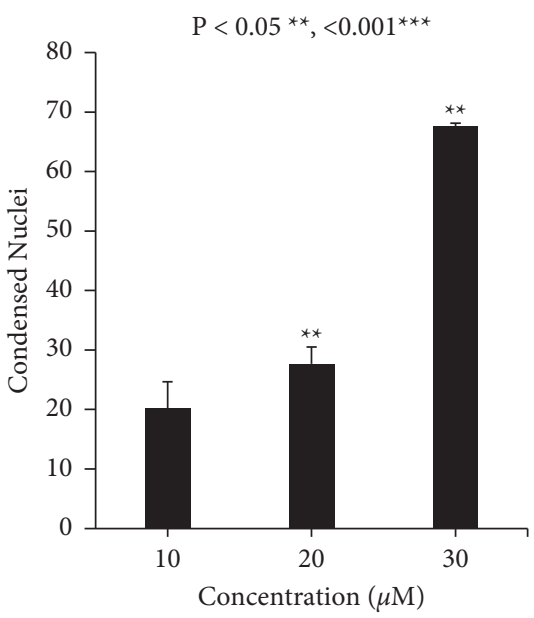

(d)

Figure 2: $\alpha$-Mangostin promotes apoptosis in MCF-7 cells. (a) $\alpha$-Mangostin induced apoptotic cell death in MCF-7 cells with Annexin-V positive staining. MCF-7 cells were treated with different concentrations of $\alpha$-mangostin followed by staining with Annexin- $\mathrm{V}$ and propidium iodide before flow cytometry analysis. (b) $\alpha$-Mangostin induced apoptotic cell death in MCF-7 cells through the activation of caspase. The caspase activity of $\alpha$-Mangostin-treated cells was measured using pGLO sensor -30F DEVD. (c) $\alpha$-Mangostin induced nuclei condensation in MCF-7 cells. MCF-7 cells were treated with different concentrations of $\alpha$-mangostin followed by DAPI staining and imaging using fluorescence microscopy. (d) Quantitative measurement of condensed nuclei in MCF-7 cells is described in (c).

apoptosis signaling mediated by MOAP-1 and BAX, leading to BAX oligomerization and mitochondrial dysfunction. The data were further supported by the evidence obtained from MCF-7 cells and spheroids stably expressed HA-MOAP-1, which showed enhanced chemosensitization mediated by $\alpha$-mangostin. In contrast, the MCF-7 cells and spheroids stably expressed Myc-BCL-XL were resistant to chemosensitization mediated by $\alpha$-mangostin even when the protein level of Myc-BCL-XL was reduced due to protein degradation.

MOAP-1 protein level was shown to be stabilized or upregulated by various apoptosis stimuli with different mechanisms of action, including FTY720, Etoposide, TRAIL, and Thapsigargin, suggesting potential cross-talks and convergence of cell signaling mechanism [59, 60]; however, this study highlights that $\alpha$-mangostin promotes the upregulation of MOAP-1 and interaction of MOAP-1 with act-BAX leading to oligomerization of BAX, downregulation of BCL-XL, the release of mitochondrial Cyt. C, and activation of caspase. Since both endogenous and overexpressed MOAP-1 proteins were upregulated by $\alpha$-mangostin in $\alpha$-mangostin-treated MCF-7 cells independent of gene promoter, the mechanisms of action of $\alpha$-mangostin may involve post-translational stabilization of MOAP-1 protein.

The proteasome inhibitor, MG132, was reported to stabilize polyubiquitinated MOAP-1 from degradation by proteasome, while UBR5 and APC/C ${ }^{\text {cdh1 }}$ E3 ubiquitin ligases 


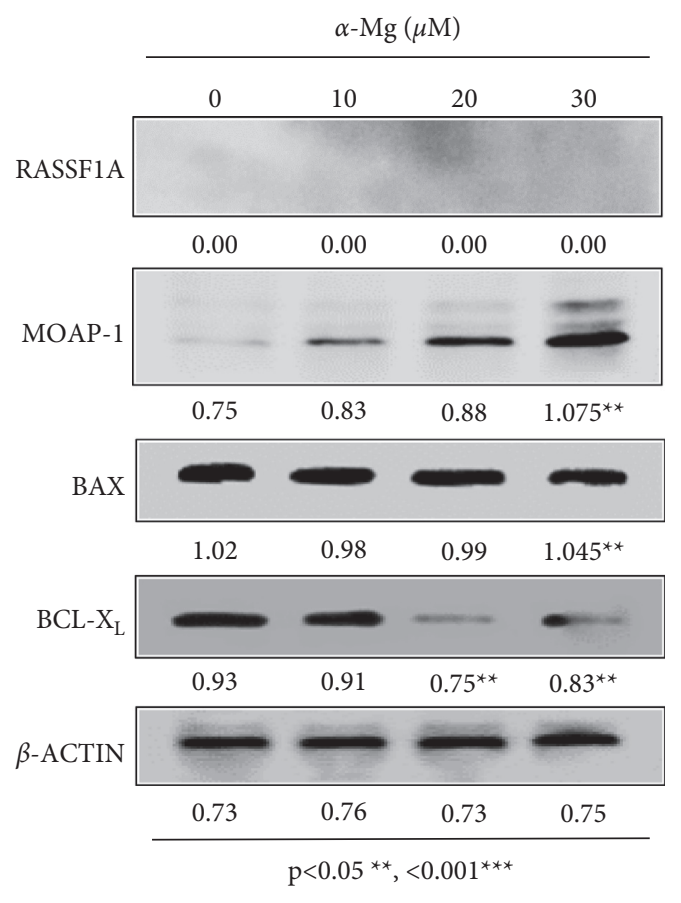

(a)

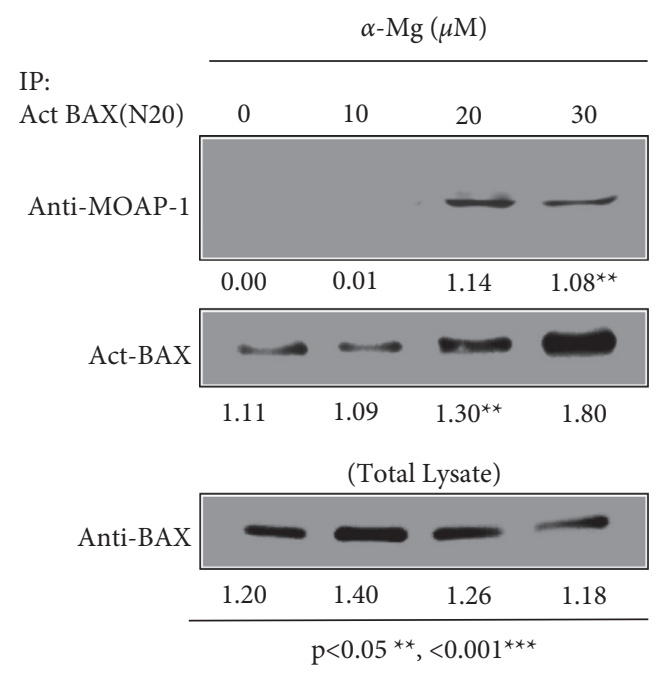

(c)

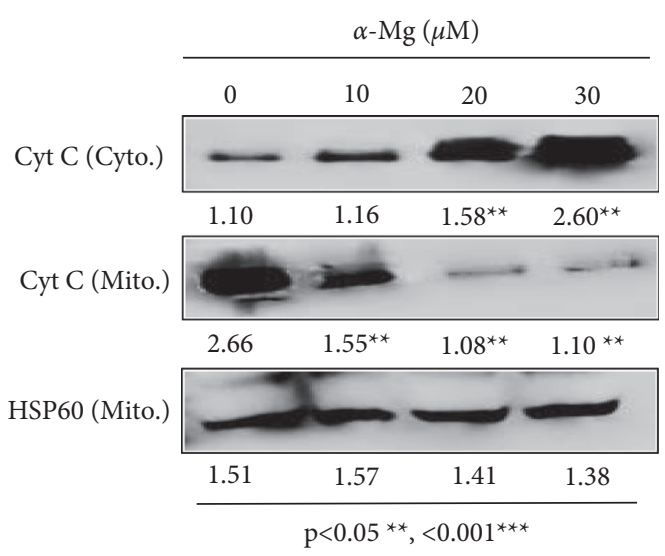

(b)

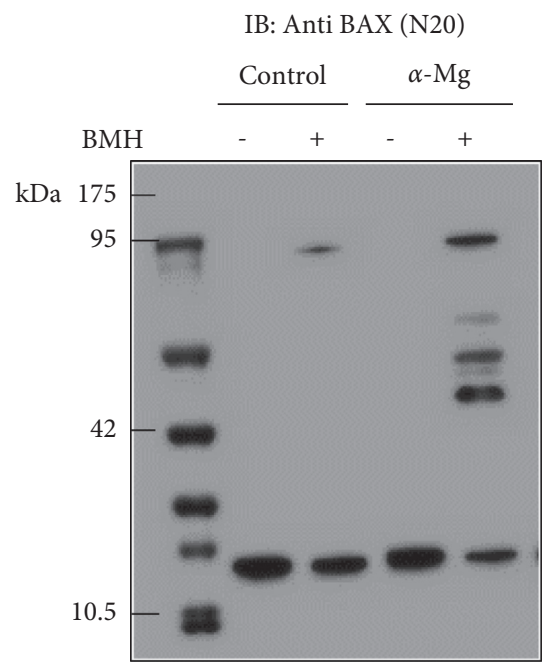

(d)

FIGURE 3: $\alpha$-Mangostin induces the upregulation of endogenous MOAP-1 and promotes the interaction of MOAP-1 with activated BAX. (a) $\alpha$-Mangostin induced the upregulation and the downregulation of endogenous MOAP-1 and BCL-XL, respectively. MCF-7 cells were treated with different concentrations of $\alpha$-mangostin, and the cell lysates were prepared for immunoblot analysis using antibodies specific for each of the indicated proteins. (b) $\alpha$-Mangostin induced the release of mitochondrial Cyt. (C) After treatment, the cytosol and mitochondria fractions were prepared for immunoblot analysis. (c) $\alpha$-Mangostin promoted the interaction of MOAP-1 with activated BAX in MCF-7 cells. After treatment, the cell lysates were prepared for coimmunoprecipitation with N20 antibody specific for activated BAX (Act. BAX) followed by immunoblot analysis of the immunoprecipitants. (d) Oligomerization of activated BAX in MCF-7 cells treated with $\alpha$-mangostin $(30 \mu \mathrm{M})$. After treatment, the cell lysates were prepared for crosslinking with BMH followed by immunoblot analysis with an anti-BAX antibody. The protein bands were quantified using ImageJ [46].

target MOAP-1 for degradation [59, 61, 62]. Besides, TRIM39 was reported to promote the stabilization of MOAP-1 through negative regulation of APC/C $C^{\mathrm{cdh} 1}[61,63]$. The mechanism in which $\alpha$-mangostin mediates upregulation of MOAP-1 warrants further investigation to identify the potential regulation of MOAP-1 protein or its transcript by $\alpha$-mangostin. Also, strategies that lead to enhanced expression and stabilization of MOAP-1 protein in cancer cells are likely to confer tangible benefits for therapeutic intervention in cancer. Future investigations are required to further examine the potential impact of $\alpha$-mangostin for cancer treatment. 


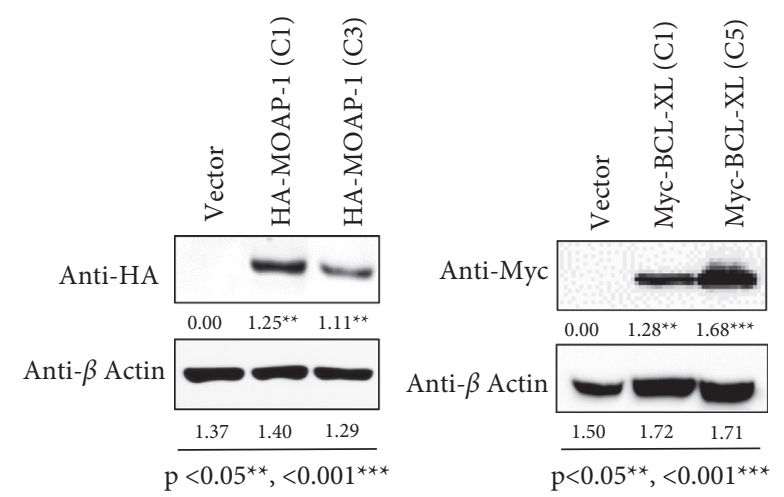

(a)

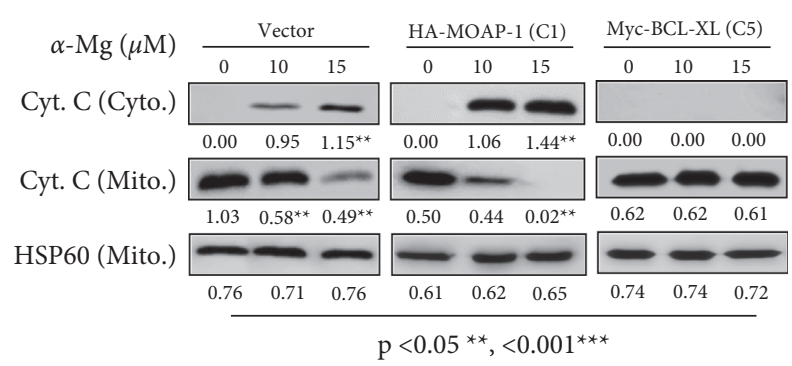

(c)

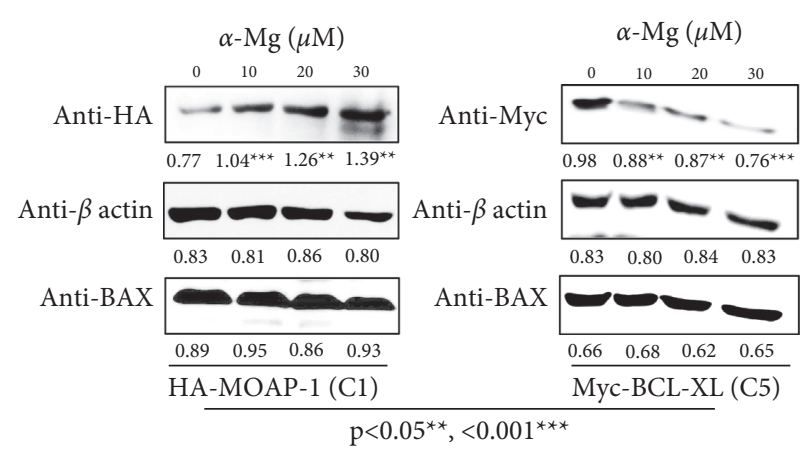

(b)

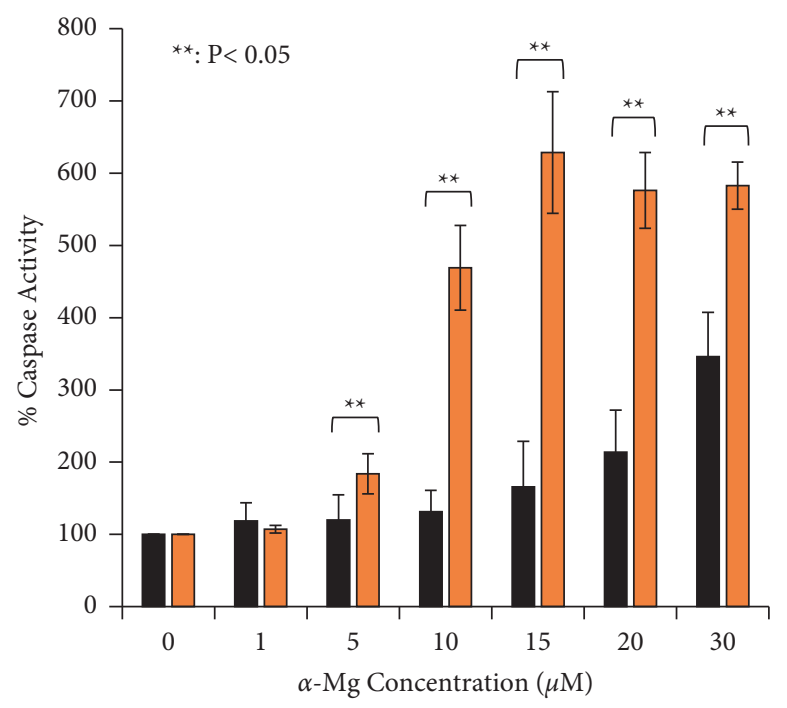

Vector

$\square$ HA-MOAP-1 (C1)

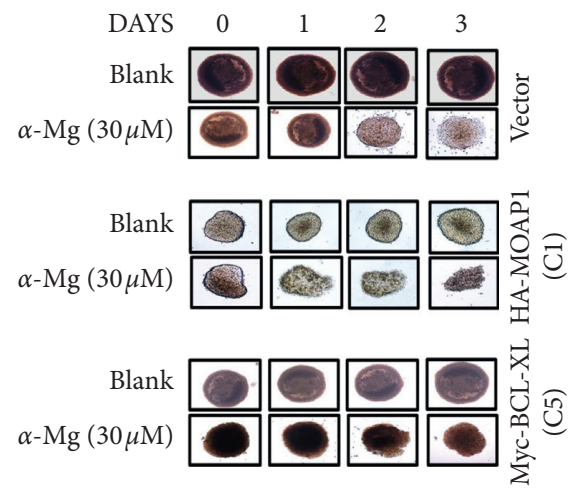

(e)

FIgURE 4: Continued. 


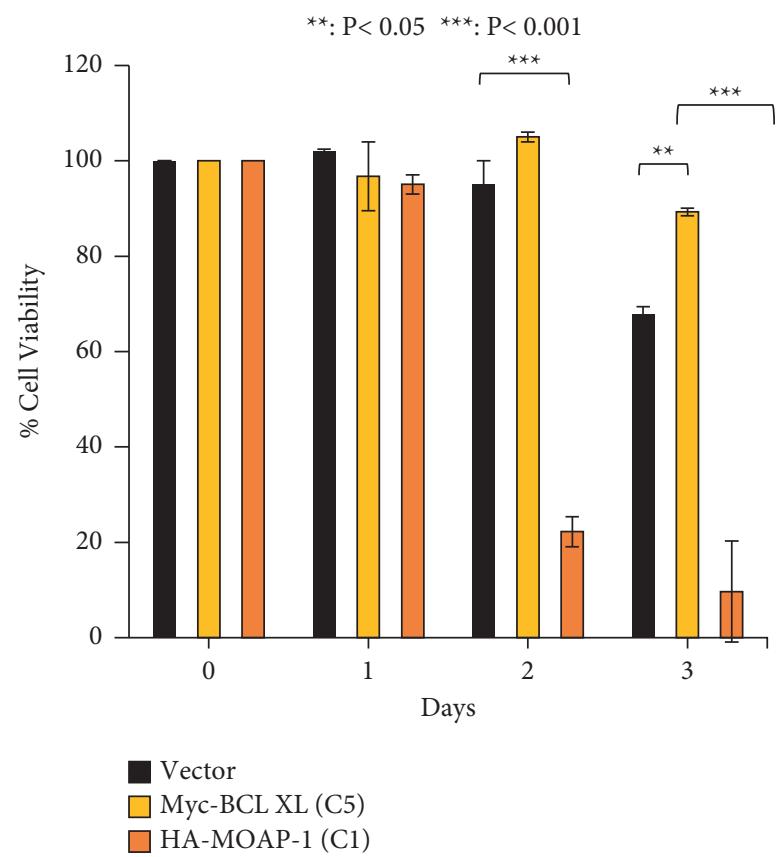

(f)

FIGURE 4: $\alpha$-Mangostin enhances chemosensitization of MCF-7 cells and spheroids stably expressed HA-MOAP-1. (a) Western blot analysis of MCF-7 stable clones stably expressed HA-MOAP-1 or Myc-BCL-XL. The cell lysates of the stable clones were prepared and analyzed on a Western blot using the indicated antibodies. (b) The upregulation of HA-MOAP-1 and downregulation of Myc-BCL-XL proteins in the MCF-7 stable clones treated with $\alpha$-mangostin. The cell lysates of the stable clones were prepared and analyzed with the indicated antibodies. $\alpha$-Mangostin increased dose-dependent release of mitochondrial Cyt. C (c) and activation of caspase (d) of HA-MOAP-1 stable clone. The cytosolic and mitochondria fractions were prepared for immunoblot analysis with the indicated antibodies. The caspase activity of the treated cells was measured using pGLO sensor-30F DEVD. (e) Depletion of MCF-7 spheroid cells stably expressed HA-MOAP-1 by $\alpha$-mangostin. Morphology of the spheroid MCF-7 cells treated with $\alpha$-mangostin. (f) Quantification of the cell viability of the spheroid cells as described in (e). Cell viability of the spheroid cells was quantified at the indicated time after treatment with $\alpha$-mangostin. The protein bands were quantified using ImageJ [46].

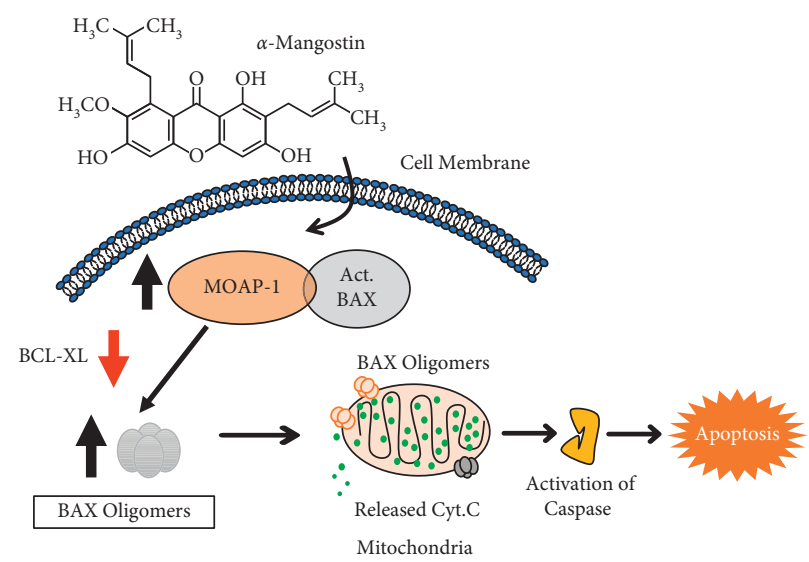

FIGURE 5: Schematic representation depicting the responses of MOAP-1, BAX, BCL-XL, and mitochondria to $\alpha$-mangostin.

\section{Conclusions}

The cytotoxic activity of $\alpha$-mangostin in human cancer cells involves the upregulation of MOAP-1 tumor suppressor and activated BAX as well as the interaction of the upregulated MOAP-1 with act-BAX, leading to apoptosis signaling, including BAX oligomerization, downregulation of BCL-XL, the release of mitochondrial Cyt.C, and caspase activation. Cancer cells overexpressing MOAP-1 exhibit enhanced sensitivity, while cancer cells overexpressing BCL-XL are resistant to $\alpha$-mangostin-mediated apoptosis, suggesting that $\alpha$-mangostin induces apoptosis through mitochondria signaling pathway involving the activation of both MOAP-1 and act-BAX while downregulating the expression of BCL-XL. 


\section{Abbreviations}

$\begin{array}{ll}\text { KDa: } & \text { KiloDalton } \\ \text { FBS: } & \text { Fetal bovine serum } \\ \text { CHAPS: } & \text { 3-[(3-Cholamidopropyl) dimethylammonio]-1- } \\ & \text { propanesulfonate } \\ \text { EDTA: } & \text { Ethylenediaminetetraacetic Acid } \\ \text { SDS- } & \text { Sodium dodecyl sulfate polyacrylamide gel } \\ \text { PAGE: } & \text { electrophoresis } \\ \text { APC: } & \text { Allophycocyanin } \\ \text { MTT: } & \text { 3-(4,5-Dimethylthiazol-2-yl)-2,5- } \\ & \text { diphenyltetrazolium bromide } \\ \text { PI: } & \text { Propidium iodide } \\ \text { RIPA: } & \text { Radio-immunoprecipitation assay } \\ \text { ECL: } & \text { Enhanced chemiluminescence } \\ \text { HEPES: } & \text { (4-(2-hydroxyethyl)-1-piperazineethanesulfonic } \\ & \text { acid } \\ \text { PEI: } & \text { Polyethyleneimine } \\ \text { BCA: } & \text { Bicinchoninic acid assay } \\ \text { DTT: } & \text { Dithiothreitol } \\ \text { FTY 720: } & \text { Fingolimod } \\ \mu M: & \text { Micromolar } \\ \text { MG132: } & \text { N-[(phenylmethoxy)carbonyl]-L-leucyl-N- } \\ \text { TNF: } & \text { [(1R)-1-formyl-3-methylbutyl]-L-leucinamide } \\ \text { TRAIL: } & \text { Tumor necrosis factor } \\ \text { MOAP- } & \text { Modulator of apoptosis 1 } \\ \text { 1: } & \\ \text { PBS: } & \text { Phosphate-buffered saline } \\ \text { DAPI: } & \text { 4',6-Diamidino-2-phenylindole } \\ \text { BMH: } & \text { Bismaleimidohexane } \\ \text { DMSO: } & \text { Dimethyl sulfoxide } \\ \text { DMEM: } & \text { Dulbecco's modified eagle medium } \\ \text { TLC: } & \text { Thin layer chromatography } \\ \text { HPLC: } & \text { High-performance liquid chromatography } \\ \text { IB: } & \text { Immunoblot } \\ \text { IP: } & \text { Cytochrome C } \\ & \text { Immunoprecipitation. } \\ \text { Myt.C: } & \end{array}$

\section{Data Availability}

Data are available upon request by contacting the corresponding author.

\section{Conflicts of Interest}

The authors declare that they have no conflicts of interest.

\section{Acknowledgments}

The research was supported by Sunway University Research Grant (EXT-SST-DBS-BWH-2018-01) and FRGS (Ministry of Higher Education, Malaysia) Research Grant (FRGS/1/ 2020/SKK06/SYUC/01/1). The authors would like to express their appreciation to $\mathrm{Ng}$ Bee Ngoh for the generous donation of G. mangostana that was used to prepare the plant extracts.

\section{References}

[1] L. Yu, M. Zhao, B. Yang, Q. Zhao, and Y. Jiang, "Phenolics from hull of Garcinia mangostana fruit and their antioxidant activities," Food Chemistry, vol. 2007, 2007.

[2] P. Moongkarndi, N. Kosem, O. Luanratana, S. Jongsomboonkusol, and N. Pongpan, "Antiproliferative activity of Thai medicinal plant extracts on human breast adenocarcinoma cell line," Fitoterapia, vol. 75, no. 3-4, pp. 375-377, 2004.

[3] K. Nakatani, N. Nakahata, T. Arakawa, H. Yasuda, and Y. Ohizumi, "Inhibition of cyclooxygenase and prostaglandin E2 synthesis by $\gamma$-mangostin, a xanthone derivative in mangosteen, in C6 rat glioma cells," Biochemical Pharmacology, vol. 63, no. 1, pp. 73-79, 2002.

[4] A. Sato, H. Fujiwara, H. Oku, K. Ishiguro, and Y. Ohizumi, " $\alpha$-Mangostin induces Ca2+-ATPase-dependent apoptosis via mitochondrial pathway in PC12 cells," Journal of Pharmacological Sciences, vol. 95, no. 1, pp. 33-40, 2004.

[5] Y. Sakagami, M. Iinuma, K. G. N. P. Piyasena, and H. R. W. Dharmaratne, "Antibacterial activity of $\alpha$-mangostin against vancomycin resistant Enterococci (VRE) and synergism with antibiotics," Phytomedicine, vol. 12, no. 3, pp. 203-208, 2005.

[6] K. Matsumoto, Y. Akao, E. Kobayashi et al., "Induction of apoptosis by xanthones from mangosteen in human leukemia cell lines," Journal of Natural Products, vol. 66, no. 8, pp. 1124-1127, 2003.

[7] D. Obolskiy, I. Pischel, N. Siriwatanametanon, and M. Heinrich, "Garcinia mangostanaL.: a phytochemical and pharmacological review," Phytotherapy Research, vol. 23, no. 8, pp. 1047-1065, 2009.

[8] R. Yang, P. Li, and N. Li, "Xanthones from the pericarp of Garcinia mangostana," Molecules, vol. 22, no. 5, 2017.

[9] Y. Shan and W. Zhang, "Preparative separation of major xanthones from mangosteen pericarp using high-performance centrifugal partition chromatography," Journal of Separation Science, vol. 33, no. 9, pp. 1274-1278, 2010.

[10] F. A. Abdalrahim, "Quantification of $\alpha$-, $\beta$ - and $\gamma$-mangostin in Garcinia mangostana fruit rind extracts by a reverse phase high performance liquid chromatography," Journal of $\mathrm{Me}$ dicinal Plants Research, vol. 6, no. 29, 2012.

[11] A.-R. Han, J.-A. Kim, D. D. Lantvit et al., "Cytotoxic xanthone constituents of the stem bark of Garcinia mangostana (mangosteen)," Journal of Natural Products, vol. 72, no. 11, pp. 2028-2031, 2009.

[12] M. Y. Ibrahim, N. M. Hashim, A. A. Mariod et al., " $\alpha$-Mangostin from Garcinia mangostana Linn: an updated review of its pharmacological properties," Arabian Journal of Chemistry, vol. 9, no. 3, pp. 317-329, 2016.

[13] N. L. E. E. Hae, Y. J. A. N. G. Hye, and J. K. I. M. Hyeong, "Antitumor and apoptosis-inducing effects of $\alpha$-mangostin extracted from the pericarp of the mangosteen fruit (Garcinia mangostana L.) in YD-15 tongue mucoepidermoid carcinoma cells," International Journal of Molecular Medicine, vol. 37, pp. 939-948, 2016.

[14] X. Quan, Y. Wang, and X. Ma, “ $\alpha$-Mangostin induces apoptosis and suppresses differentiation of 3T3-L1 cells via inhibiting fatty acid synthase." PLoS One, vol. 7, p. e33376, 2012.

[15] R. Aukkanimart, T. Boonmars, and P. Sriraj, "In vitro and in vivo inhibitory effects of $\alpha$-mangostin on cholangiocarcinoma 
cells and allografts," Asian Pacific Journal of Cancer Prevention, vol. 18, pp. 707-713, 2017.

[16] D. Lee, Y. O. Choi, and K. H. Kim, "Protective effect of $\hat{\mathrm{I}} \pm$-mangostin against iodixanol-induced apoptotic damage in LLC-PK1 cells," Bioorganic \& Medicinal Chemistry Letters, vol. 26, pp. 3806-3809, 2016.

[17] C.-M. Chen, S.-C. Hsieh, and C.-L. Lin, "Alpha-Mangostin suppresses the metastasis of human renal carcinoma cells by targeting MEK/ERK expression and MMP-9 transcription activity," Cellular Physiology and Biochemistry, vol. 44, no. 4, pp. 1460-1470, 2017.

[18] S. R. M. Ibrahim, G. A. Mohamed, and M. A. Elfaky, "Mangostanaxanthone VII, a new cytotoxic xanthone from Garcinia mangostana," Zeitschrift fur Naturforschungs Section C Journal of Bioscience, vol. 73, pp. 185-189, 2018.

[19] G. A. Mohamed, A. M. Al-Abd, A. M. El-halawany, H. M. Abdallah, and S. R. M. Ibrahim, "New xanthones and cytotoxic constituents from Garcinia mangostana fruit hulls against human hepatocellular, breast, and colorectal cancer cell lines," Journal of Ethnopharmacology, vol. 198, pp. 302-312, 2017.

[20] S. Raguz and E. Yagüe, "Resistance to chemotherapy: new treatments and novel insights into an old problem," British Journal of Cancer, vol. 99, pp. 387-391, 2008.

[21] S.-T. Pan, Z.-L. Li, Z.-X. He, J.-X. Qiu, and S.-F. Zhou, "Molecular mechanisms for tumour resistance to chemotherapy," Clinical and Experimental Pharmacology and Physiology, vol. 43, pp. 723-737, 2016.

[22] T. A. d'Amato, "Chemotherapy resistance and oncogene expression in non-small cell lung cancer," The Journal of Thoracic and Cardiovascular Surgery, vol. 133, pp. 352-363, 2007.

[23] T. Veerasamy, S. Eugin Simon, and K. O. Tan, "Emerging strategies for sensitization of therapy resistant tumors toward cancer therapeutics by targeting the Bcl-2 family, TGF- $\beta$, $\mathrm{Wnt} / \beta$-Catenin, RASSF and miRNA regulated signaling pathways," The International Journal of Biochemistry \& Cell Biology, vol. 137, p. 106016, 2021.

[24] T. R. Zembower, Epidemiology of Infections in Cancer Patients, Springer, Berlin, Germany, 2014.

[25] R. W. Steele, "Managing infection in cancer patients and other immunocompromised children," The Ochsner Journal, vol. 12, pp. 202-210, 2012.

[26] C. Kyi, M. D. Hellmann, J. D. Wolchok, P. B. Chapman, and M. A. Postow, "Opportunistic infections in patients treated with immunotherapy for cancer," Journal for ImmunoTherapy of Cancer, vol. 2, p. 19, 2014.

[27] S. Vyas, E. Zaganjor, and M. C. Haigis, "Mitochondria and cancer," Cell, vol. 166, no. 3, pp. 555-566, 2016.

[28] P. E. Porporato, N. Filigheddu, J. M. B. S. Pedro, G. Kroemer, and L. Galluzzi, "Mitochondrial metabolism and cancer," Cell Research, vol. 28, no. 3, pp. 265-280, 2018.

[29] A. Giménez-Cassina and N. N. Danial, "Regulation of mitochondrial nutrient and energy metabolism by BCL-2 family proteins." Trends in Endocrinology and Metabolism, vol. 26, pp. 165-175, 2015.

[30] E. Er, L. Oliver, and P. F. Cartron, "Mitochondria as the target of the pro-apoptotic protein Bax," Biochimica et Biophysica Acta-Bioenergetics, vol. 1757, pp. 1301-1311, 2006.

[31] T. Gallenne, F. Gautier, and L. Oliver, "Bax activation by the BH3-only protein Puma promotes cell dependence on antiapoptotic Bcl-2 family members," The Journal of Cell Biology, vol. 185, pp. 279-290, 2009.
[32] K. G. Wolter, Y. Te Hsu, and C. L. Smith, "Movement of Bax from the cytosol to mitochondria during apoptosis," The Journal of Cell Biology, vol. 139, pp. 1281-1292, 1997.

[33] P. E. Czabotar, D. Westphal, and G. Dewson, "Bax crystal structures reveal how $\mathrm{BH} 3$ domains activate Bax and nucleate its oligomerization to induce apoptosis," Cell, vol. 152, pp. 519-531, 2013.

[34] K. O. Tan, N. Y. Fu, and S. K. Sukumaran, "MAP-1 is a mitochondrial effector of Bax." Proceedings of the National Academy of Sciences of the United States of America, vol. 102, pp. 14623-14628, 2005.

[35] C. J. Foley, H. Freedman, and S. L. Choo, "Dynamics of RASSF1A/MOAP-1 association with death receptors," Molecular and Cellular Biology, vol. 28, pp. 4520-4535, 2008.

[36] K. O. Tan, K. M. L. Tan, and S. L. Chan, "MAP-1, a novel proapoptotic protein containing a $\mathrm{BH} 3$-like motif that associates with bax through its bcl-2 homology domains," Journal of Biological Chemistry, vol. 276, pp. 2802-2807, 2001.

[37] M. D. Vos, A. Dallol, and K. Eckfeld, "The RASSF1A tumor suppressor activates bax via MOAP-1," Journal of Biological Chemistry, vol. 281, pp. 4557-4563, 2006.

[38] R. S. Whelan, K. Konstantinidis, and A.-C. Wei, "Bax regulates primary necrosis through mitochondrial dynamics." Proceedings of the National Academy of Sciences of the United States of America, vol. 109, pp. 6566-6571, 2012.

[39] E. Raemy and J. C. Martinou, "Involvement of cardiolipin in tBID-induced activation of BAX during apoptosis," Chemistry and Physics of Lipids, vol. 179, 2014.

[40] S. Bleicken, M. Classen, and P. V. L. Padmavathi, "Molecular details of Bax activation, oligomerization, and membrane insertion," Journal of Biological Chemistry, vol. 285, pp. 6636-6647, 2010.

[41] R. Eskes, S. Desagher, B. Antonsson, and J. C. Martinou, "Bid induces the oligomerization and insertion of Bax into the outer mitochondrial membrane," Molecular and Cellular Biology, vol. 20, pp. 929-935, 2000.

[42] T. Kuwana, N. H. Olson, W. B. Kiosses, B. Peters, and D. D. Newmeyer, "Pro-apoptotic Bax molecules densely populate the edges of membrane pores," Scientific Reports, vol. 6, no. 1, 2016.

[43] Y. H. Lee, S. W. Pang, and E. Revai Lechtich, "Tricistronic expression of MOAP-1, Bax and RASSF1A in cancer cells enhances chemo-sensitization that requires $\mathrm{BH} 3 \mathrm{~L}$ domain of MOAP-1," Journal of Cancer Research and Clinical Oncology, vol. 146, 2020.

[44] S. E. Simon, A. Numan, F. A. Jayakumar, M. Khalid, and K. O. Tan, "Investigating the impact of UV irradiated graphene oxide on human breast cancer cells," Materials Today Communications, vol. 29, p. 102830, Dec. 2021.

[45] W. Mark, L. Michael, and L. Smith, "Expression microarray analysis reveals genes associated with in vitro resistance to cisplatin in a cell line model," Acta Oncologica, vol. 46, pp. 651-658, 2007.

[46] C. A. Schneider, W. S. Rasband, and K. W. Eliceiri, "NIH Image to ImageJ: 25 years of image analysis," Nature Methods, vol. 9, pp. 671-675, 2012.

[47] P. Boukamp, R. T. Petrussevska, and D. Breitkreutz, "Normal keratinization in a spontaneously immortalized aneuploid human keratinocyte cell line," The Journal of Cell Biology, vol. 106, pp. 761-771, 1988.

[48] M. Y. Li, J. Q. Liu, and D. P. Chen, "P68 prompts the epithelial-mesenchymal transition in cervical cancer cells by transcriptionally activating the TGF- $\beta 1$ signaling pathway," Oncology Letters, vol. 15, pp. 2111-2116, Feb. 2018. 
[49] A. Novilla, D. S. Djamhuri, and N. Fauziah, "Cytotoxic activity of mangosteen ( Garcinia mangostana L.) peel extract and $\alpha$-mangostin toward leukemia cell lines (HL-60 and K-562)," Journal of Natural Remedies, vol. 16, pp. 52-59, Aug. 2016.

[50] C.-H. Lee, T.-H. Ying, and H.-L. Chiou, "Alpha-mangostin induces apoptosis through activation of reactive oxygen species and ASK1/p38 signaling pathway in cervical cancer cells," Oncotarget, vol. 8, p. 47425, 2017.

[51] H. H. Kwak, I. R. Kim, H. J. Kim, B. S. Park, and S. Bin Yu, " $\alpha$-mangostin induces apoptosis and cell cycle arrest in oral squamous cell carcinoma cell," Evidence-based Complementary and Alternative Medicine, vol. 2016, 2016.

[52] V. G. A. Arciuch, M. E. Elguero, J. J. Poderoso, and M. C. Carreras, "Mitochondrial regulation of cell cycle and proliferation," Antioxidants and Redox Signaling, vol. 16, no. 10, p. 1150, 2012.

[53] S. H. Dho, B. E. Deverman, and C. Lapid, "Control of Cellular Bcl-xL Levels by Deamidation-Regulated Degradation," PLoS Biology, vol. 11, no. 6, 2013.

[54] N. Edison, Y. Curtz, and N. Paland, "Degradation of Bcl-2 by XIAP and ARTS promotes apoptosis," Cell Reports, vol. 21, no. 2, pp. 442-454, 2017.

[55] V. Andreu-Fernández, M. Sancho, and A. Genovés, "Bax transmembrane domain interacts with prosurvival Bcl-2 proteins in biological membranes," Proceedings of the $\mathrm{Na}$ tional Academy of Sciences of the United States of America, vol. 114, pp. 310-315, 2017.

[56] Y. H. Lee, S. W. Pang, and K. O. Tan, "PNMA2 mediates heterodimeric interactions and antagonizes chemo-sensitizing activities mediated by members of PNMA family," Biochemical and Biophysical Research Communications, vol. 473, no. 1, 2016.

[57] Y. H. Lee, S. W. Pang, C. L. Poh, and K. O. Tan, "Distinct functional domains of PNMA5 mediate protein-protein interaction, nuclear localization, and apoptosis signaling in human cancer cells," Journal of Cancer Research and Clinical Oncology, vol. 142, pp. 1967-1977, 2016.

[58] S. W. Pang, C. Lahiri, C. L. Poh, and K. O. Tan, "PNMA family: Protein interaction network and cell signalling pathways implicated in cancer and apoptosis," Cell Signaling Technology, vol. 45, 2018.

[59] N. Y. Fu, S. K. Sukumaran, and V. C. Yu, "Inhibition of ubiquitin-mediated degradation of MOAP-1 by apoptotic stimuli promotes Bax function in mitochondria." Proceedings of the National Academy of Sciences of the United States of America, vol. 104, pp. 10051-10056, 2007.

[60] F. Wang, W. Tan, and D. Guo, "Altered expression of signaling genes in Jurkat cells upon FTY720 induced apoptosis," International Journal of Molecular Sciences, vol. 11, pp. 3087-3105, 2010.

[61] N.-J. Huang, L. Zhang, and W. Tang, "The Trim39 ubiquitin ligase inhibits APC/CCdh1-mediated degradation of the Bax activator MOAP-1," The Journal of Cell Biology, vol. 197, pp. 361-367, 2012.

[62] K. Matsuura, N.-J. Huang, K. Cocce, L. Zhang, and S. Kornbluth, "Downregulation of the proapoptotic protein MOAP-1 by the UBR5 ubiquitin ligase and its role in ovarian cancer resistance to cisplatin," Oncogene, vol. 36, pp. 1698-1706, 2017.

[63] S. S. Lee, N. Y. Fu, and S. K. Sukumaran, "TRIM39 is a MOAP1-binding protein that stabilizes MOAP-1 through inhibition of its poly-ubiquitination process," Experimental Cell Research, vol. 315, pp. 1313-1325, 2009. 